\title{
An HIV Prevention Toolkit For Unaccompanied Men Who Perform Agricultural Labor
}

\author{
Keith V. Bletzer ${ }^{1}$, Alicia Gonzales ${ }^{2}$, Monica Saavedra ${ }^{3}$, Sylvia Partida ${ }^{4}$ and Bobbi Ryder ${ }^{4}$ \\ ${ }^{1}$ Arizona State University \\ ${ }^{2}$ National Center for Farmworker Health \\ ${ }^{3}$ Austin Affiliate of Susan G. Komen for the Cure \\ ${ }^{4}$ National Center for Farmworker Health
}

\begin{abstract}
Farm workers are vulnerable to irregular employment and job uncertainty. These conditions increase the likelihood they will find themselves in living and working sites where risk for HIV is present. Considering the exacerbated risk for HIV among unaccompanied male agricultural workers, a national non-profit farm worker health training and technical assistance organization planned and developed an HIV prevention-education toolkit to assist migrant and community health centers with HIV education to reach this population of vulnerable male farm workers. This article reviews iterative development of the toolkit in three phases, outlines the process whereby community input grounded the product in ways that were culturally responsive and linguistically appropriate for the target population of male farm workers, explores implications of the project as a national initiative to reduce HIV risks in a sizeable but dispersed community, and briefly describes how the overall project was assessed through community-based strategies.
\end{abstract}

(c) 2012 Californian Journal of Health Promotion. All rights reserved.

Keywords: HIV/AIDS, prevention-education, agricultural labor, unaccompanied male farm workers, migrant and community health centers

\section{Introduction}

An estimated two-thirds of undocumented workers in this country are employed in shortterm low-wage jobs that are predominant in agriculture and food processing (Passel, 2006). These jobs are full-time and part-time, or "day labor" (Karjanen, 2011). Regardless of where they were born and raised, 80 to 86 percent of all farm workers speak Spanish and nearly fourfifths are Latino (National Agricultural Workers Survey, 2005). Given shifting immigration laws and public attitudes toward the undocumented, those farm workers born outside this country face difficulties that change in form and increase in intensity on crossing the border (Martinez, 2002).
Conditions in U.S. agriculture include low-paid work, little job security, inadequate work-site safety with negligible regulation (Griffith \& Kissam, 1995), no 'safety net' when injured (Barndt, 2002), and stressful lifestyles (Grzywacz, Quandt \& Arcury, 2008; Magaña \& Hovey, 2003). Farm workers are mobile: an estimated 17 percent travel more than 75 miles "to follow-the-crops," 44 percent work yearround in a "home-base," and 39 percent "commute" to work within 75 miles of homebase (National Agricultural Workers Survey, 2005). Their mean age at 29 includes the age range most susceptible for HIV/AIDS (ages 1844), owing to the likelihood that this cohort will engage in risk behavior. Experiencing economically precarious employment 
(Rothenberg, 1998), awkward living arrangements (Benson, 2008) and difficult work conditions (Cartwright, 2011; Duke, 2011; Holmes, 2011), farm workers face variable levels of risk for HIV (Painter, 2008). They reportedly have low to moderate levels of knowledge on the transmission modes for HIV and the asymptomatic features of AIDS (Fitzgerald et al, 2003; Ford et al, 2001). Given their mobility, variable levels of risk can shift from one season to the next, as farm labor crews re-constitute themselves from previous years, and corresponding levels of knowledge can fluctuate among those seasonally present in a given temporary locale.

More than fifty percent of male farm workers report they have female partners, but most travel alone when working. Although more women from Mexico are entering this country, few travel as "migrant workers" and fewer travel with children (National Agricultural Workers Survey, 2005). A macro-analysis by Thomas Painter (2008) of research to 2007 and an earlier East Coast study by Claire Viadro and Jo Anne Earp (2000) identified as the primary risks for HIV among farm workers, the work-generated lifestyles of men that travel unaccompanied by a female partner, alongside the conditions of limited English skills and minimal cultural capital to enable access to taken-for-granted health services. Prevention knowledge is part of this cultural capital, when men emulate actions of co-workers to avoid risk by using condoms and reducing contacts with casual partners and sex workers (Organista, Carrillo \& Ayala, 2004; Organista et al, 2000; Organista et al, 1997a; Organista et al, 1997b)

This article describes the process whereby a national health training and technical assistance organization developed and pilot-tested HIV prevention materials designed for male farm workers. The goal was to create an educational toolkit for the national system of Migrant and Community Health Centers (M/CHCs), which has responsibility for servicing the medical needs of farm workers. The toolkit was intended for lay health workers, health educators and case managers. In this article, we examine the project rationale, its iterative development, lay health worker training and toolkit pilot-tests, and the final educational end-product.

\section{Methods}

To reach vulnerable, unaccompanied, lowliteracy male farm workers at risk for HIV/AIDS, the National Center for Farmworker Health (NCFH) conducted a national initiative to develop and pilot-test a culturally responsive HIV education-prevention curriculum/toolkit. Named Hombres Preparados ("Prepared Men") based on a mission "to prepare male farm workers for safer sex," the project was guided by the premise that high-risk farm workers had less HIV knowledge and were unlikely to practice prevention behaviors or to access HIV/AIDS testing-counseling. The project underwent three phases: (a) needs assessment and focus groups, (b) toolkit formulation and community-based pilot-tests, and (c) finalization of the toolkit with national availability.

Material for this article came from a needs assessment, focus groups, field notes and an evaluation report submitted to the funding source. Ten Migrant and Community Health Centers in seven states with large farm labor populations (AZ, CA, FL, NM, NY, ME, and TX) acted as field sites. Because most participants were monolingual (a few were bilingual), Spanish was the main language for training sessions with lay health workers, and focus groups for farm workers, whereas the focus groups for lay health workers mixed English with Spanish. In the West, two indigenous participants attended as a husbandand-wife, and in the East, one individual identified as white. Otherwise, everyone in the various training sessions self-identified as Latino.

\section{First Phase: Needs Assessment and Focus Groups}

Project staff introduced the project and conducted a needs assessment through phone interviews with clinic representatives from the $\mathrm{M} / \mathrm{CHC}$ system, to determine the availability of prevention education materials for farm workers. Contacts were scripted to general questions on available prevention services and/or community 
Bletzer, K. V., Gonzales, A., Saavedra, M., Partida, S., \& Ryder, B. / Californian Journal of Health Promotion 2012, Volume 10,

education, followed by specific inquiries on the inclusion of HIV/AIDS in outreach, staff training on HIV/AIDS and in cultural competency, available HIV testing services, and seasonal intensification of outreach. Despite these efforts no curriculum was currently available and HIV/AIDS prevention-education services for farm workers were limited. Staff training on HIV/AIDS was minimal to nonexistent and the materials in clinic lobbies were broadly designed for Latinos (English/Spanish). Lack of linguistically and culturally appropriate HIV prevention materials aimed at farm workers highlighted the need to emphasize 'language' and 'culture' (Taylor, 2007) to create an effective HIV prevention-education toolkit.

Focus Groups: Six focus groups were convened and taped/transcribed, and the transcripts were content-summarized. Groups were arranged by staff from active $\mathrm{M} / \mathrm{CHC}$ clinics in home-base states in three regions of the country with concentrated agricultural communities; in each state, M/CHC staff recruited local lay health workers with experience in outreach and men with farm labor experience (range two to 50 years). Forty-two persons participated in separate focus groups in Florida ( 8 farm workers, 7 promotores), Texas (4 farm workers, 6 promotores), and California (8 farm workers, 9 promotores). These separate interviews for each group upheld an expectation for participant homogeneity (Hollander, 2004). Corroborating previous research on farm worker focus groups, the facilitator encouraged sharing on issues that were relevant to men and women (Madriz, 1998), adjusted the order of questions (Napolitano et al 2002), and permitted flexibility in timing responses (Perilla et al, 1998). Questions to lay health worker focus groups considered what they felt were 'best practices' in outreach versus questions to the farm worker men on their experiences with lay health workers, preferred learning styles, and prior use of testing/counseling services, if any. The project coordinator facilitated all focus groups, accompanied by a note-taker and occasionally the consultant.

\section{Findings}

Most lay health workers had general HIV/AIDS knowledge, whereas most the farm workers had minimal knowledge. Corroborating comments from the lay health workers, who typically conducted outreach in labor camps, male farm workers preferred information in visual and auditory format, such as video and informal talks, when it was communicated by someone they trusted. They appreciated lay health workers; varied in attitudes toward testing, treatment and confidentiality; revealed that they often listened to the radio when alone. Lay health workers in contrast were challenged by men who "expressed guilt" (culpable) when their spouse became infected or when they indicated little willingness to get tested (muy díficil). They noted that men "felt embarrassed" (ponen rojos) whereas migrant women often "giggled" (de risa) over condom demonstrations, and they agreed that male farm workers were skilled in use of indirect questions to share their concerns and to ask questions on AIDS. More than half the male farm workers in focus groups had taken the test for HIV at least once (11 of the total 20 farm workers: 8 of 8 in CA, 3 of 8 in FL, but none of the 4 in TX).

Analysis of focus group data generated presentation practices to best serve farm workers. Four concerns were identified. (1) Machismo: some men felt they were, or they were said to feel, invincible to HIV; several denied a need for condom protection and stated unwillingness to seek treatment, if infected. Others believed that machismo represented a big responsibility to family and community. (2) Localism: home remedies were recommended by both farm workers and lay health workers over commercial medications; alternative healers were consulted for advice and treatment. (3) Religion: the church was said to impede prevention efforts but few recommended ways to resolve the dilemma. (4) Trust: many farm workers would accept sensitive information oneon-one and/or in groups from someone who could create and maintain confianza (trust) by communication style, whether female or male, 
Hispanic or non-Hispanic. Camp-based strategies that were culturally-responsive and visually appealing were deemed to be the most effective.

\section{Second Phase: Developing and Testing the Toolkit}

HIV prevention materials underwent multiple drafts through review with the consultant, health educators, and medical professionals. These 'expert panel' consultations took place online and in person. Emphasizing 'popular education' strategies proven effective with farm workers, the early curriculum included a manual of lessons and slide presentation, pre-test and posttest survey, and condom packets with bilingual instructions. The curriculum was first tested in four pilot training sessions with lay health workers and iteratively revised through five fullday training sessions at $\mathrm{M} / \mathrm{CHC}$ clinics in separate states of three regions and in three regional sessions in two states. The test sites were similar to those chosen for focus groups: high concentration of farm workers in a small rural community and provision of HIV care and services through an $\mathrm{M} / \mathrm{CHC}$ clinic. The 12 sessions were evaluated by a pre-test and posttest with an increase in HIV/AIDS knowledge of $35.6 \%$ (high 23\%; low 47\%). All together 133 lay health workers received full-day training and instruction in using the curriculum, and they provided 75 to 100 [15-20 X 5 sites] posttraining, education practicum "pilot-tests" to 307 farm workers. In addition, 269 persons were referred for HIV testing (209 through the pilottests, plus 60 of 98 in the local/regional training sessions).

Rather than review the revised materials through focus groups, project staff organized local versions of 'expert panels' of lay health workers at five sites who conducted presentations with male farm workers. These practicum pilot-tests followed a lesson plan and took place after the training sessions. Most were one-on-one or in small groups depending on available time. The lay health workers who conducted pilot-tests provided feedback on this experience through post-training evaluation forms, submitted by sponsoring $\mathrm{M} / \mathrm{CHC}$ clinics. This evaluative information emphasized appropriateness of the curriculum and how well it was understood by farm workers.

Curriculum Development: After each training workshop and the corresponding pilot-tests, staff incorporated into the curriculum suggestions by workshop trainees, annotated session notes, and post-training feedback from in-the-field pilottests. Revisions were iteratively responsive to lay health worker needs. Each of twelve M/CHC sites that sponsored a training workshop in effect received an increasingly improved version.

Prepared by NCFH staff with extensive experience in creating community-based media and training materials, a flipchart replaced the photo-novel (fotonovela) to eliminate struggles that participants had in reading text. Like photonovels, the portable flipcharts were configured with Latino artwork in an effective photo-novel style for use by/for Latinos/Latinas. Instructions on the reverse side permitted presenters to read aloud. After curriculum testing in local settings, lay health workers reported that farm workers found flipchart and photo-novel designs appealing, and the lay health workers in turn found materials manageable. Flipcharts contained easy-to-read bilingual instructions on the reverse side and visuals with text on the front. Bilingual instructions for condom packets were revised with attention to vernacular language and the visual diagrams that accompanied the instructions were simplified.

Claudia y Diego, a video produced by the Blue Ridge Health Center, replaced an older, urbanoriented video, Mi Hermano (released in 1992 by American Red Cross). Participants who were familiar with the replacement video reported that they liked the language-oriented message, which relied on word play, voice inflection, and humor. Communication styles matched those of farm workers and lay health workers observed in focus groups and training sessions. One woman in a condom discussion, for example, offered a comment grounded in humor: "My aunt says that she doesn't use a condom. My mom says, 'It's like eating candy with a wrapper" (Tengo una tía que dice que ella no usa el condón. Mi mamá dice, 'Es como comer un dulce con el papelito'). Audience laughter supported her 
Bletzer, K. V., Gonzales, A., Saavedra, M., Partida, S., \& Ryder, B. / Californian Journal of Health Promotion 2012, Volume 10,

Issue 1, 64-75

remark. In Mexico, candy can refer to sexual relations (Hirsch, 2009:82-83) and plastic covers and wrappers are euphemisms for condoms (Bletzer, 1995:189).

\section{Third Phase: Packaging and Promoting the Product}

For a final test of the curriculum before a general, but equally knowledgeable audience, project staff presented a near-final draft at annual migrant health forums in three regions of the country. Apart from frontline service providers much like those at the local/regional trainings and focus groups, forum participants included farm labor advocates, clinic administrators, health educators, college-trained providers, intervention specialists, media technicians and others with expertise on reaching and educating agricultural workers. Feedback obtained in the 90-minute workshops that presented the product permitted project staff to finalize curriculum revision. At the same time the presentations in essence served "to debut" the free availability of an HIV prevention toolkit.

Final Curriculum: In the final version, the manual cover was re-designed to fit its intent as

\section{Figure 1}

\section{Cover of the HIV/AIDS Education Manual with the Table of Contents.}

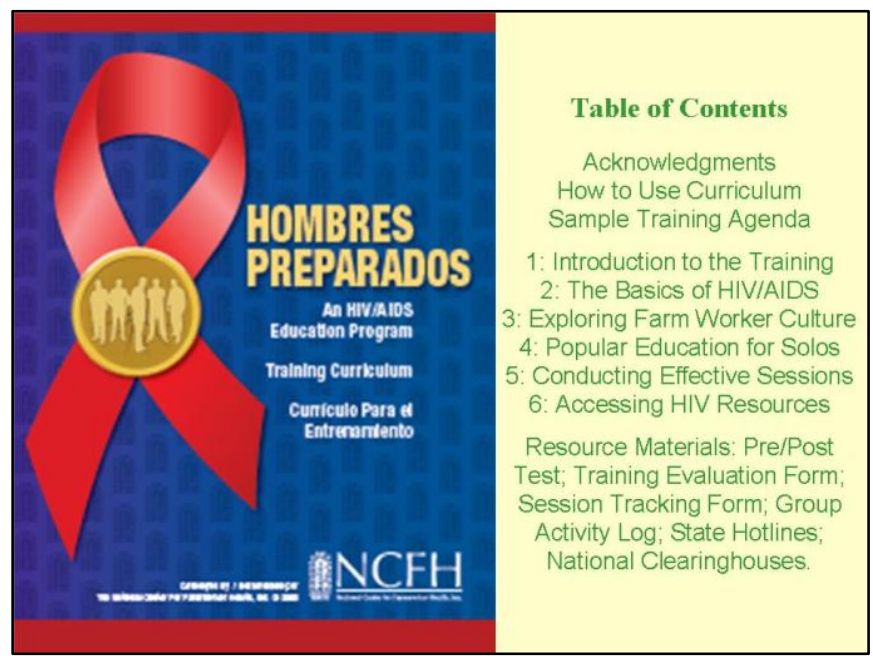

a guide for HIV instruction to farm workers and lay health workers (Figure 1) and a slide show was included on CD-ROM. Lessons were reduced to six, which were outlined by guidepoints in the margins (Figure 2). Each lesson varied from one to two and a half hours $(n=11$ total) and contained four to ten objectives $(n=34)$, four to eight topics $(n=30)$, one to six handouts $(n=20)$, and zero to six activities $(n=14)$. Chapter themes covered the basics of HIV/AIDS, farm worker culture; popular education for male farm workers; effective HIV/AIDS prevention practices; potential resources. The 110-page manual included easyto-follow bilingual instructions. Concerns uncovered in the focus groups were treated responsively in the manual (especially machismo, localism, and trust). "Cultural Views of Gender Roles and Sexuality" (Topic 5 of Lesson 3, pp. 57-59), for example, discusses male/female sexuality. "How to Conduct Culturally Competent HIV/AIDS Sessions in Your Community" (Topic 6 of Lesson 3, pp. 5963) provides guidelines for local initiatives and information throughout the manual describes local resources such as testing sites. Figure 2 is an excerpt on networking from Topic 1 in Lesson 2 (p. 90 and p. 92).

Figure 2

\section{Sample page from HIV/AIDS Education Manual}

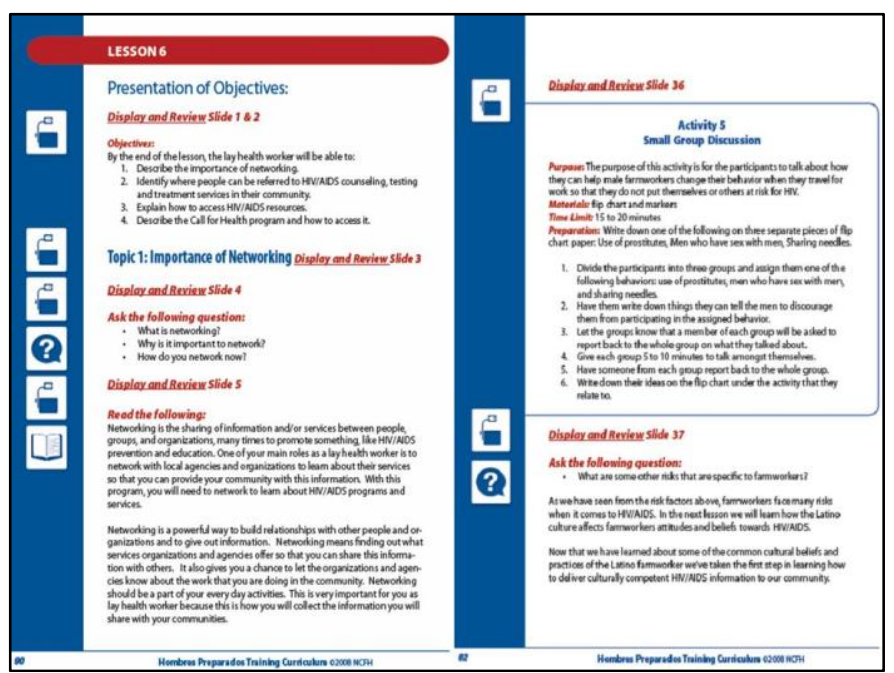

Showing margin guide points, color-coded headings to identify slide display, text review, discussion question, and "boxed" activity 
Final Flip-Chart: Text and visuals in the English/Spanish flip-chart take a personcentered view of an outreach worker. A threepanel cover shows Rodolfo (farm worker), Pedro (health worker), and Pedro as he instructs Rodolfo, Miguel and Juan in a typical encounter site, namely, a male labor camp (Figure 3). Farm workers are given primacy, as Rodolfo appears in the first panel. In the middle, Pedro receives HIV training from Dr. Cortez, which builds credibility. In the third, Pedro holds a condom packet, the key to prevention, as he provides instruction, dispels myths on transmission and clarifies the workers' questions. Visible to the audience, each of the eighteen flip-chart pages mixes photos with large-letter bilingual text and diagrams (Figure 4). The text in English/Spanish on the reverse side can be read aloud or summarized. The final page provides a toll-free number to the national service 'Call for Health' that responds to confidential health inquiries. Compared to HIV prevention photo-novels in comic-book format for distribution to farm workers, the flip-chart was designed for outdoor/indoor presentations. Scenes in a "labor camp" (campito) include a cabin (casita) and truck (troca) as common icons that serve as selfidentifiers for the target population. To increase relevancy, boxed speech-bubbles and stylized thought-bubbles correct the misconceptions with accurate HIV prevention information. Key concerns uncovered in focus groups were sensitively treated, including, "Why Men Don't Want to Get the Test" (p. 12), "Reasons Why Juan Wants to Get the Test" (p. 13), and "Men Talk about Why They Don't Like Condoms" (p. 16).

\section{Discussion}

We briefly describe results from the program evaluation and explore the impact of infrastructure enhancement across the $\mathrm{M} / \mathrm{CHC}$ system generated by project implementation and availability of the curriculum. These broad results go beyond more immediate learning by selected male farm workers and lay health workers who benefited from the training workshops and pilot-testing.
Figure 3

\section{Cover of Flip Chart}

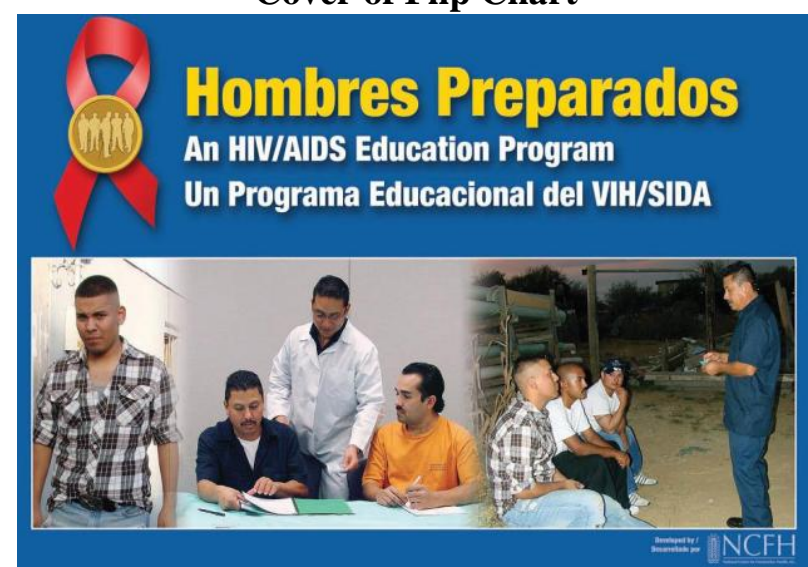

Main themes are visually abstracted. Left: Rodolfo (farm worker). Middle: Pedro (lay health worker) receives prevention-education training from Dr. Cortez. Right: Pedro instructs farm workers, outdoors, in a labor camp. Throughout the manual, Rodolfo and Pedro are identified by their shirts, and the two remaining workers in T-shirts are distinguished by hat and no hat, respectively.

Figure 4

Sample Page From Flip Chart

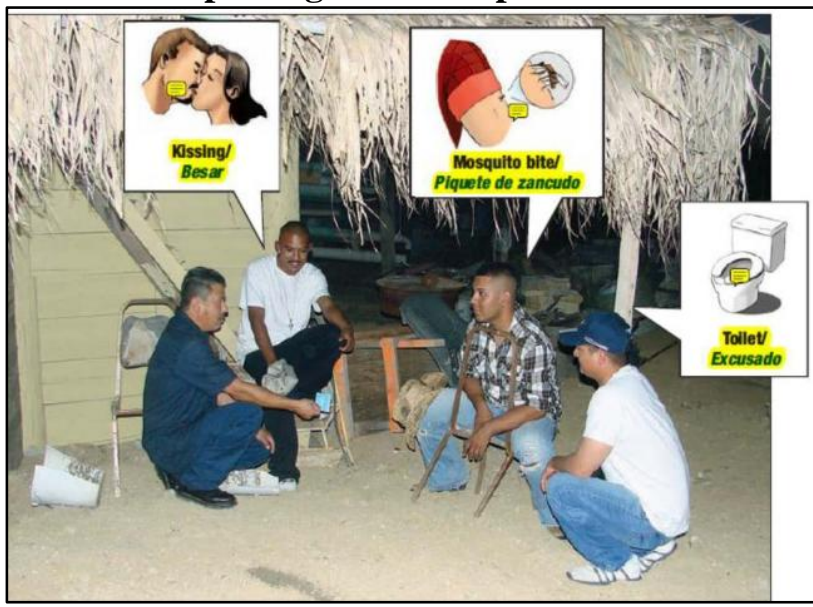

Transmission myths are discussed with lay health worker (Pedro): "kissing" (Juan), "mosquito bites" (Rodolfo) and "toilet seats" (Miguel).

Project evaluation was formative rather than summative. 'Evaluative checkpoints' elicited data on general satisfaction and specific data for curriculum content (Chen, 2002). Protocols were updated to represent changes in the prevention 
curriculum, which was continually revised and re-formatted. All ten sites met or surpassed the expected goals identified for culturallyresponsive materials: effectiveness of curriculum for agencies serving farm workers, increased knowledge on HIV/AIDS, and satisfaction with training, measured by pre-test and post-test.

Baseline services offered by the national organization demonstrated substantial increase in referrals, requests for materials and toll-free calls (Table 1). HIV/AIDS referrals primarily dealt with cases requiring care and services: at baseline, these numbered 250 per year. Increases occurred each year; by the end of three years, the number more than tripled to 1,780. Baseline requests for media and materials were estimated at 115 per year; this number increased greatly each year. After doubling the second and third years, the national agency upgraded its computer capacity to handle increases in requests. Finally, the toll-free calls to 'Call for Health' with its baseline estimate of 100 per year, increased tenfold the first year. From-the-field calls declined to half this amount the second and third years, but remained higher than baseline. Staff noted that decreases coincided with public attitudes on immigration that worsened over this period, as farm workers "made themselves less visible... less willing to access services" (consultant field notes).

Table 1

Project Outcomes

\begin{tabular}{lcccccc}
\hline & $\begin{array}{c}\text { HIV/AIDS } \\
\text { Referrals }\end{array}$ & $\begin{array}{c}\text { 12-month } \\
\text { Increase }\end{array}$ & $\begin{array}{c}\text { Material } \\
\text { Requests }\end{array}$ & $\begin{array}{c}\text { 12-month } \\
\text { Increase }\end{array}$ & $\begin{array}{c}\text { Toll-Free } \\
\text { Calls }\end{array}$ & $\begin{array}{c}\text { 12-month } \\
\text { Increase }\end{array}$ \\
\hline *Pre-Start & $\mathrm{N}=$ & $\mathrm{N}(\%)$ & $\mathrm{N}=$ & $\mathrm{N}(\%)$ & $\mathrm{N}=$ & $\mathrm{N}(\%)$ \\
Year-One & 375 & (baseline) & $115^{\mathrm{a}}$ & (baseline) & 102 & (baseline) \\
Year-Two & 562 & $187(75 \%)$ & 305 & $190(165 \%)$ & 528 & $426(417 \%)$ \\
Year-Three & 843 & $281(112 \%)$ & 192 & $77(67 \%)$ & 529 & $427(418 \%)$ \\
Total & 1,780 & 593 & 594 & 249 & 2,076 & 1,770 \\
\hline
\end{tabular}

a) Online dissemination was upgraded before project initiation

Throughout the three-year project, NCHF services for farm worker organizations were strengthened. Designed to respond to inquiries on immunization and vaccinations, and treatment and prevention, specialists for the national toll-free call-in referral service ('Call for Health'), for example, were trained to handle HIV/AIDS calls. To further update their services, the call-center mapped testingcounseling sites by zip and area codes in twenty states with heavy farm labor.

To promote institutional support for the HIV prevention toolkit, presentations at the three regional migrant stream forums acted as publicity messages to market the curriculum at the same time the presenter received requests for services. Interest in the toolkit stemmed from word-of-mouth communication that began with regional focus groups and workshops. This strategy of public presentations strengthened national infrastructure through public relations and by actions, parallel to processes of community-level interventions that increased public knowledge in the epidemic's early years. Building infrastructure increases local 
receptivity for individual and group education initiatives (Vinh-Thomas, Bunch \& Card, 2003), which open opportunities for services and interventions for those at high risk (Kreuter et al, 2002; Wilson \& Miller, 2003).

Farm workers and lay health workers were primary and secondary targets, respectively. Given a wide distribution of farm workers across the country, materials designed for the national $\mathrm{M} / \mathrm{CHC}$ system would be cost-efficient across 900-plus clinics that provide services to more than thirteen million persons per year. Each outreach worker is trained to identify client needs, extend needed knowledge, provide materials, offer screenings, keep records, and prepare reports (Mack, Uken \& Powers, 2006; Reinschmidt et al, 2006). As providers, M/CHC outreach staff is hired "to mirror" the recipients they reach and teach. They embody a cultural affinity that facilitates communication and increases clinical adherence. Like farm workers, they have spent time outside this country and/or have resided in other states. Observations at training sessions, for example, noted a word play for AIDS, when farm workers and lay health workers transformed the Spanish term SIDA into Sí da "It really gives" [infects]. This phrase initially was a slogan distributed by CONASIDA (national AIDS agency) throughout Mexico and it has appeared on Spanish brochures brought into this country (consultant field notes).

Since the late 1980s when funds became available for minority HIV education, efforts occasionally appeared to provide HIV services for farm workers. Ideas were shared through the regional migrant forums. Until the national training and technical assistance agency revised its online resource library for the national project, access to HIV/AIDS resources for farm workers was limited to local circulation by "second readers," abetted by photocopy and scan technology. The project created an interest in materials that continued beyond the three-year project period (consultant field notes). Following its completion, the HIV toolkit was made available to health centers and clinics that form the M/CHC system and to all other interested organizations.

\section{Limitations}

The main project limitation was lack of a formal quantitative assessment, owing to funding that emphasized curriculum/toolkit development. Summative follow-up on its use and the behavioral impact through health centers and clinics was not conducted. General ideas were limited to that shared with project staff in time allotted for questions-and-answers during formal presentations and/or casual conversations at regional conferences. Given constraints, postproject evaluative data were anecdotal on acceptance of the curriculum and effectiveness as an educational toolkit, rather than formal evaluation and quantitative analysis of behavioral change. After the project concluded, informal "overwhelmingly positive" communications continued by both email and telephone on use of the photo-novel and flipchart/curriculum (consultant field notes).

\section{Conclusion}

Activist discourse takes the position that HIV has a potential to extend itself formidably among agricultural workers. In the early years, community discourse centered this idea with the popular phrase, "Are agricultural workers HIVprone?" (¿Son los que trabajan en los labores Sidosos?). A limited number of small-scale epidemiological investigations gave occasional glimpses at the shifting levels of HIV among these people of mobility. The extent to which HIV was reaching this community never received a sustained institutional response for surveillance or prevention. Nonetheless, the need for HIV/AIDS education for this population was not forgotten.

Limited knowledge of HIV/AIDS has been present among farm workers since early in the epidemic. Known by farm labor advocates as hombres solos, unaccompanied males are the most forgotten segment of this population. Competing priorities discourage even large agencies from seeking funds to reach beyond current programs to sponsor initiatives. Small agencies with limited services that rarely mount large-scale projects are less likely to shift to HIV education or AIDS care and services. Thus, the national project in developing prevention materials provided a reprieve from limited funds 
to rejuvenate with intellectual capital the HIV/AIDS capacity of the M/CHC system and community-based agencies interested in HIV prevention outreach/education.

Crucial to culturally and linguistically appropriate construction of the HIV prevention toolkit was inclusion of vernacular concepts to meet the challenge of machismo with promising practices of confianza that would be responsive to local needs. Language and culture continually evolve at the same time that they retain stable elements that enable consistent and comprehensive communication (Whitley, Everhart \& Wright, 2006; Martin et al, 2005). Given the ongoing re-constitution of this extensive population, efforts through community partnerships show promise. The HIV prevention curriculum/toolkit incorporated local experiences of farm workers and lay health workers to produce a linguistically and culturally appropriate model in easy-tounderstand language. Schematic layout of this prevention-education model of would be: Local to National (assess-build-evaluate-adapt) \| National to Local (distribute-disseminate)

Shifting membership too numerous for face-toface interaction and re-constitution from localeto-locale brings into focus the challenges and relevance of linguistically appropriate and culturally-responsive education for farm workers (Fink, 2003; Millard \& Chapa, 2004). To reach a mobile population scattered over numerous rural areas requires a national system that targets high-activity areas and the many locations where farm workers are found. A national initiative can reach a homogeneous, scattered population (Robbins, 2009), but it requires an integrated trans-local format for effective education (Goździak \& Bump, 2008). Regional health forums, for example, originated in the desire to integrate planning and dissemination of effective models and up-to-date 'promising practices' across a spectrum of services for staff at $\mathrm{M} / \mathrm{CHC}$ centers. The forums pre-dated electronic technology and online communication, which continue the mission of disseminating up-to-date materials and protocols and procedural guidelines for the clinics. By making materials available online and electronically, they become part of the public domain and available to groups that contemplate or plan HIV education initiatives.

How long the work of HIV education, and corresponding AIDS care and services, will be able to continue in this strengthened infrastructure depends on action initiatives and local groups, as well as community agencies that are willing and fiscally able to effectively meet the multiple needs of farm workers locally, regionally and nationally. HIV prevention education initiatives for farm workers have been, at best, intermittent. Efforts to meet their needs can teach us about the locally-relevant prevention requisites of other mobile peoples that face ambiguity and conditions of irregular employment in labor-intensive physicallydemanding work settings.

\section{References}

Barndt D. (2002). Tangled routes: Women, work, and globalization on the tomato trail. Lanham, MA: Rowman and Littlefield Publishers, Inc.

Benson P. (2008). El campo: Facility and structural violence in farm labor camps. Cultural Anthropology, 23(4), 589-629.

Bletzer K. V. (1995). Use of ethnography in the evaluation and targeting of HIV/AIDS education among Latino farm workers. AIDS Education and Prevention, 7(2), 178-191.

Cartwright E. (2011). Immigrant dreams: Legal pathologies and structural vulnerabilities along the immigration continuum. Medical Anthropology, 30(4):475-495.

Chen H.-T. (2002). Designing and conducting participatory outcome evaluation of communitybased organizations' HIV prevention programs. AIDS Education and Prevention, 14 (Supplement A), 18-26. 
Duke M. (2011). Ethnicity, well-being, and the organization of labor among shade tobacco workers. Medical Anthropology, 30(4):409-424.

Fink L. (2003). The Maya of Morgantown: Work and community in the Nuevo New South. Chapel Hill, NC: University of North Carolina Press.

Fitzgerald K., et al. (2003). HIV/AIDS knowledge among female migrant farm workers in the Midwest. Journal of Immigrant Health, 5(1), 29-36.

Ford K., et al. (2001). AIDS knowledge and risk behaviors among Midwest migrant farm workers. AIDS Education and Prevention, 13, 551-560.

Goździak E. M., \& Bump M. N. (2008). New immigrants, changing communities: Best practices for a better America. Lanham, MA: Lexington Books.

Griffith D. \& Kissam E. (1995). Working poor: Farm workers in the United States. Philadelphia: Temple University Press.

Grzywacz J. G., Quandt S. A., \& Arcury T. A. (2008). Immigrant farm workers' health-related quality of life: An application of the job demands-control model. Journal of Agricultural Safety and Health, 14(1), 79-92.

Hirsch J.S. (2009). The geography of desire: Social space, sexual projects, and the organization of extramarital sex in rural Mexico. In J. S. Hirsch, H. Wardlow, D. J. Smith, H. M. Phinney, S. Parikh \& C. A. Nathanson (Eds.), The Secret: Love, Marriage, and HIV (pp. 53-83). Nashville, TN: Vanderbilt University Press.

Hollander J. A. (2004). The social contexts of focus groups. Journal of Contemporary Ethnography, 33(5), 602-637.

Holmes S. M. (2011). Structural vulnerability and hierarchies of ethnicity and citizenship on the farm. Medical Anthropology, 30(4):425-449.

Karjanen D. (2011). "Less documented" workers and the changing U.S. economy. Open Anthropology Journal, 4, 24-32.

Kreuter M. W., et al. (2002). Achieving cultural appropriateness in health promotion programs: Targeted and tailored approaches. Health Education Behavior, 30(2), 133-146.

Mack M., Uken R., \& Powers J. (2006). People improving the community's health: Community Health Workers as agents of change. Journal of Health Care for Poor and Underserved, $17(1), 16-25$.

Madriz E. I. (1998). Using focus groups with lower socioeconomic status Latina women. Qualitative Inquiry, 4(1), 114-128.

Magaña C. G. \& Hovey J. D. (2003). Psychosocial stressors associated with Mexican migrant farm workers in the Midwest United States. Journal of Immigrant Health, 5(2), 75-86.

Martin M., et al. (2005). The evaluation of a Latino community health worker HIV prevention program. Hispanic Journal of Behavioral Services, 27(3), 371-384.

Martínez R. (2002). Crossing over: A Mexican family on the migrant trail. New York, NY: Holtzbrinck.

Millard A. \& Chapa J. (2004). Apple pie and enchiladas: Latino newcomers in the rural Midwest. Austin, TX: University of Texas Press.

Napolitano M., et al. (2002). The dynamic process of focus groups with farm workers: The Oregon experience. Journal of Immigrant Health, 4(4), 177-182.

National Agricultural Workers Survey, 2005. Washington, DC: U.S. Department of Labor. Available at: http://www.doleta.gov/agworker/naws.cfm. Accessed December 11, 2010, February 7, 2011. 
Organista K. C., et al. (1997a). Psychosocial predictors of condom use in Mexican migrant laborers. Interamerican Journal of Psychology, 31, 77-90.

Organista K. C., et al. (1997b). Survey of condom-related beliefs, behaviors and perceived social norms in Mexican migrant laborers. Journal of Community Health, 22(3), 185-198.

Organista K. C., et al. (2000). Predictors of condom use in Mexican migrant laborers. American Journal of Community Psychology, 28(2), 245-265.

Organista K. C., Carrillo H., \& Ayala G. (2004). HIV prevention with Mexican migrants: Review, critique, and recommendations. JAIDS, 37 (Supplement 4), S227-S239.

Painter T. M. (2008). Connecting the dots: When the risks of HIV/STD infection appear high but the burden of infection is not known: The case of male Latino migrants in the southern United States. AIDS Behavior, 12(2), 213-226.

Passel J. S. (2006). The size and characteristics of the unauthorized migrant population in the U.S. with estimates based on the March 2005 Current Population Survey. Washington, DC: Pew Hispanic Center.

Perilla J. L., et al. (1998). Listening to migrant voices: Focus groups on health issues in south Georgia. Journal of Community Health Nursing, 15(4), 251-263.

Reinschmidt K. M., et al. (2006). Understanding the success of promotoras in increasing chronic disease screening. Journal of Health Care for Poor and Underserved, 17(2), 256-264.

Robins S. (2009). Foot soldiers of global health: Teaching and preaching AIDS science and modern medicine on the frontline. Medical Anthropology, 28(1), 81-107.

Rothenberg D. (1998). With these hands: The hidden world of migrant farm workers today. New York, NY: Harcourt Brace and Company.

Taylor J. J. (2007). Assisting or compromising intervention? The concept of 'culture' in biomedical and social research on HIV/AIDS. Social Science and Medicine, 64, 965-975.

Viadro C. I. \& Earp J. A. L. (2000). The sexual behavior of married Mexican immigrant men in North Carolina. Social Science and Medicine, 50, 723-735.

Vinh-Thomas P., Bunch M. M., \& Card J. J. (2003). A research-based tool for identifying and strengthening culturally competent and evaluation-ready HIV/AIDS education programs. AIDS Education and Prevention, 15(6), 481-498.

Whitley E. M., Everhart R. M., \& Wright R. A. (2006). Measuring return on investment of outreach by community health workers. Journal of Health Care for Poor and Underserved, 17(1), 6-15.

Wilson B. D. M. \& Miller R. L. (2003). Examining strategies for culturally grounded HIV prevention, AIDS Education and Prevention, 15(2), 184-202.

Author Information

Keith V. Bletzer, $\mathrm{PhD}, \mathrm{MPH}^{*}$

School of Human Evolution and Social Change

Arizona State University

PO Box 2402

Tempe, Arizona 85287-2402

Telephone: (480)965-6215

Fax: (480)965-7671

Email: keith.bletzer@asu.edu 
Bletzer, K. V., Gonzales, A., Saavedra, M., Partida, S., \& Ryder, B. / Californian Journal of Health Promotion 2012, Volume 10, Issue 1, 64-75

\author{
Alicia Gonzales, MSSW \\ National Center for Farmworker Health, \\ Buda, Texas \\ Monica Saavedra, MPH, MCHES \\ Austin Affiliate of Susan G. Komen for the Cure, Austin, \\ Texas \\ Sylvia Partida, MA \\ National Center for Farmworker Health \\ Buda, Texas \\ Bobbi Ryder \\ National Center for Farmworker Health \\ Buda, Texas \\ * corresponding author
}

